\title{
Dimensi Mutu Pelayanan Kebidanan terhadap Kepuasan Pasien Program Jampersal
}

\author{
Quality Dimensions of Midwifery Care on Patient Satisfaction Jampersal \\ (Delivery Assurance) Program
}

\author{
Herlina Susmaneli, Ani Triana
}

\section{Sekolah Tinggi Ilmu Kesehatan Hang Tuah Pekanbaru}

\begin{abstract}
Abstrak
Dalam rangka menurunkan angka kematian ibu dan angka kematian bayi untuk pencapaian Millennium Development Goals, ditetapkan kebijakan bahwa setiap ibu yang melahirkan, biaya persalinannya ditanggung oleh pemerintah melalui Program Jampersal, namun dalam pelaksanaannya masih ditemukan ketidakpuasan pasien terhadap pelayanan kebidanan. Penelitian ini bertujuan untuk menganalisis pengaruh dimensi mutu pelayanan kebidanan terhadap kepuasan pasien program Jampersal meliputi keandalan bidan, ketanggapan bidan, jaminan bidan, empati dan bukti langsung. Penelitian ini dilakukan di RSUD Rokan Hulu dengan populasi semua pengguna Jampersal yaitu sebanyak 92 orang dan pada penelitian ini seluruh populasi dijadikan sampel. Penelitian ini menggunakan desain potong lintang. Pengumpulan data dilakukan dengan data primer dan data sekunder. Dilakukan analisis data yaitu analisis univariat, analisis bivariat (kai kuadrat) dan analisis multivariat (regresi logistik ganda). Proporsi pasien program Jampersal yang memiliki kepuasan terhadap mutu pelayanan kebidanan sebanyak 67 orang (72,8\%) dari 92 sampel. Variabel independen dengan hubungan yang signifikan dengan kepuasan pasien program Jampersal adalah variabel bukti langsung dengan nilai $p<$ $0,05(0,003)$.
\end{abstract}

Kata kunci: Dimensi mutu, jampersal, kepuasan pasien

\footnotetext{
Abstract

In order to reduce maternal mortality rate and infant mortality rate, in achieving the Millennium Development Goals set policy, that every mother who gave birth, her labor costs borne by the government through assurance of delivery program, but in practice still found dissatisfaction of patients to obstetric care. This study aimed to analyze the influence of the quality dimensions of midwifery care on patient satisfaction assurance of delivery program include reliability midwife, responsiveness midwife, assurance midwife, and direct tangible. This study was conducted in Rokan Hulu District General Hospital with a population assurance of delivery all users and as
}

many as 92 people on the entire study population sampled. This study used a cross sectional design. The data was collected primary data and secondary data. Data analysis is performed univariate, bivariate analysis (chisquare) and multivariate analysis (Multiple Logistic Regression). The proportion of patients who had an assurance of delivery program satisfaction with the quality of obstetric care by $72.8 \%$. Independent variables with significant association with patient satisfaction assurance of delivery is a concrete manifestation of variables with $p$ value $<0.05(0.003)$.

Keywords: Dimensions of quality, assurance of delivery, patient satisfaction

\section{Pendahuluan}

Sasaran pembangunan kesehatan akhir tahun 2014 adalah meningkatnya derajat kesehatan masyarakat melalui pendekatan Millennium Development Goals (MDGs), antara lain menurunnya angka kematian bayi menjadi 24 per 1.000 kelahiran hidup, menurunnya angka kematian ibu melahirkan menjadi 118 per 100.000 kelahiran hidup. ${ }^{1}$ Istilah "tiga terlambat" dan "empat terlalu" merupakan fenomena yang paling sering terjadi dan merupakan faktor pendukung penyebab angka kematian ibu (AKI). Istilah "tiga terlambat" yaitu terlambat dalam mengenali tanda bahaya dan harus mencari pertolongan ke fasilitas kesehatan, terlambat dalam mencapai fasilitas kesehatan yang memadai, dan terlambat dalam menerima pelayanan kesehatan yang cukup memadai pada setiap tingkatan. Istilah "empat terlalu" yaitu terlalu muda untuk menikah, terlalu sering hamil, terlalu banyak melahirkan, dan terlalu tua untuk hamil. ${ }^{2}$

Alamat Korespondensi: Herlina Susmaneli, Sekolah Tinggi Ilmu Kesehatan Hang Tuah Pekanbaru, Jl. Mustafa Sari No. 5 Tangkerang Selatan Pekanbaru, Hp.085272842500,e-mail:neli_herlina@yahoo.co.id 
Menurut Riskesdas 2012, persalinan oleh tenaga kesehatan pada sasaran kelompok miskin baru mencapai sekitar $69,3 \%$, sedangkan persalinan yang dilakukan oleh tenaga kesehatan di fasilitas kesehatan mencapai $55,4 \%$. Salah satu kendala penting untuk mengakses persalinan oleh tenaga kesehatan di fasilitas kesehatan adalah keterbatasan dan ketidaktersediaan biaya sehingga diperlukan kebijakan terobosan untuk meningkatkan persalinan yang ditolong oleh tenaga kesehatan di fasilitas pelayanan kesehatan melalui kebijakan yang disebut jaminan persalinan. Jaminan persalinan dimaksudkan untuk menghilangkan hambatan finansial bagi ibu hamil untuk mendapatkan jaminan persalinan, yang di dalamnya termasuk periksa kehamilan, pelayanan nifas termasuk KB pascapersalinan, dan pelayanan bayi baru lahir. Adanya jaminan persalinan diharapkan dapat mengurangi terjadinya tiga terlambat sehingga dapat mengakselerasi tujuan pencapaian MDGs. ${ }^{3}$

Dalam rangka menurunkan AKI dan angka kematian bayi $(\mathrm{AKB})$ dan mempercepat pencapaian MDGs maka ditetapkan kebijakan, bahwa setiap ibu yang melahirkan, biaya persalinannya ditanggung oleh pemerintah melalui Program Jampersal. ${ }^{4}$ Peningkatan kepuasan pelanggan atau pasien menjadi strategi utama bagi pelayanan kesehatan di Indonesia salah satunya rumah sakit. Kepuasan pelanggan timbul bila produk atau jasa memenuhi atau melebihi harapan pelanggan. Pelanggan yang puas akan jasa atau produk yang diterimanya akan menimbulkan kognisi, afeksi, dan konasi terhadap produk atau jasa tersebut sehingga pada akhirnya muncul minat untuk menggunakan produk atau jasa tersebut. ${ }^{5}$ Hal ini membuat tempat pelayanan kesehatan harus berkompetisi agar mutu pelayanan kesehatan yang dapat diterima dan dinikmati masyarakat akan semakin baik.

Faktor manusia sebagai pemberi pelayanan publik dalam menghasilkan pelayanan yang berkualitas. Menurut Thoha, ${ }^{6}$ kualitas pelayanan kepada masyarakat sangat tergantung pada individual dan sistem yang dipakai. Dokter dan tenaga penunjang medis serta nonmedis yang bertugas di rumah sakit harus memahami cara melayani konsumen dengan baik terutama kepada pasien dan keluarga pasien, karena pasien dan keluarga pasien adalah konsumen utama di rumah sakit. Kemampuan rumah sakit dalam memenuhi kebutuhan pasien dapat diukur dari tingkat kepuasan pasien.

Data pencapaian indikator pelayanan kebidanan di unit rawat inap kebidanan RSUD Rokan Hulu berdasarkan Bed Occupancy Ratio (BOR) atau angka penggunaan tempat tidur, Average Length of Stay (ALOS) atau rata-rata lamanya pasien dirawat dan Turn Over Interval (TOI) atau tenggang perputaran pada tahun 2011 sampai dengan 2012 bahwa BOR di RSUD sudah sesuai dengan indikator $60-85 \%$. Akan tetapi ALOS dan TOI masih dibawah indikator. ${ }^{7}$ Berdasarkan studi terdahulu yang ditemukan, ada beberapa penyebab ketidakpuasan pasien menyangkut dimensi mutu layanan, seperti keandalan petugas (pemeriksaan pasien tidak tepat waktu, waktu pelayanan yang lama), ketanggapan petugas (lambatnya mendapatkan pelayanan atau pengobatan, lambatnya petugas menanggapi keluhan pasien), jaminan (petugas jaga judes dan cerewet, petugas sering salah dalam memasang infus), empati (petugas yang kurang memperhatikan pasien, petugas tidak membantu pasien ketika pasien kesulitan ke kamar mandi/makan) dan bukti langsung (ruangan yang kotor, tidak nyaman, alat-alat kebutuhan pasien rusak). Oleh karena itu, penelitian ini bertujuan untuk menganalisis pengaruh dimensi mutu pelayanan kebidanan terhadap kepuasan pasien program Jampersal meliputi keandalan bidan, ketanggapan bidan, jaminan bidan, empati, dan bukti langsung.

\section{Metode}

Penelitian ini menggunakan desain potong lintang dengan pengambilan sampel yaitu seluruh pasien pengguna Jampersal di RSUD Rokan Hulu yang berjumlah 92 orang dengan memenuhi kriteria inklusi pasien yang pernah/sedang menggunakan Jampersal dan kriteria ekslusi yaitu bukan pasien Askes, bukan pasien Jamkesda dan bukan pasien Jamkesmas. Teknik pengumpulan data ada dua yaitu data primer dan data sekunder. Cara pengumpulan data primer adalah dari hasil pengisian kuesioner dari semua variabel independen dan variabel dependen yang sumber datanya adalah responden. Pengumpulan data primer dilakukan dengan wawancara terstruktur kepada responden dengan menggunakan instrumen kuesioner yang didesain. Jika responden di tahun 2013 tidak mencukupi, peneliti mencari responden (dengan melihat data rekam medis) tahun sebelumnya sampai jumlah sampel terpenuhi. Data sekunder diperoleh dari penelusuran dokumentasi di ruang Rekam Medis dan Kebidanan RSUD Rokan Hulu.

\section{Hasil}

Berdasarkan hasil analisis univariat, sebagian besar responden mayoritas usia 20 - 35 tahun sebanyak 69 orang $(75 \%)$. Variabel wujud nyata mayoritas responden dengan hasil baik yaitu sebanyak 67 orang $(72,8 \%)$, variabel keandalan mayoritas dengan hasil baik sebanyak 52 orang $(56,5 \%)$, variabel ketanggapan mayoritas dengan hasil baik sebanyak 52 orang $(56,5 \%)$, variabel jaminan mayoritas dengan hasil baik sebanyak 78 orang $(84,8 \%)$, variabel empati mayoritas dengan hasil baik sebanyak 71 orang $(77,2 \%)$, pada variabel kepuasan mayoritas responden merasa puas sebanyak 67 orang $(72,8 \%)$ (Tabel 1).

Berdasarkan hasil analisis bivariat, terpilih seluruh variabel yang akan dimasukkan kedalam model analisis 
Tabel 1. Distribusi Responden

\begin{tabular}{llll}
\hline Variabel & Kategori & $\mathbf{n}$ & $\%$ \\
\hline \multirow{2}{*}{ Umur } & $<20$ dan $>35$ tahun & 23 & 25 \\
Bukti langsung & $20-35$ tahun & 69 & 75 \\
Kehandalan & Buruk $(<3)$ & 25 & 27,2 \\
Ketanggapan & Baik $(\geq 3)$ & 67 & 72,8 \\
& Buruk $(<2,6)$ & 40 & 43,5 \\
Jaminan & Baik $(\geq 2,6)$ & 52 & 56,5 \\
& Buruk $(<2,9)$ & 6 & 6,5 \\
Empati & Baik $(\geq 2,9)$ & 86 & 93,5 \\
& Buruk $(<3)$ & 14 & 15,2 \\
Kepuasan & Baik $(\geq 3)$ & 78 & 84,8 \\
& Buruk $(<3)$ & 21 & 22,8 \\
& Baik $(\geq 3)$ & 71 & 77,2 \\
& Tidak puas & 25 & 27,2 \\
& Puas & 67 & 72,8
\end{tabular}

Tabel 2. Hasil Seleksi Bivariat

\begin{tabular}{lll}
\hline Variabel & Nilai p & Keterangan \\
\hline Bukti langsung & 0,000 & Kandidat \\
Keandalan & 0,000 & Kandidat \\
Ketanggapan & 0,003 & Kandidat \\
Jaminan & 0,000 & Kandidat \\
Empati & 0,000 & Kandidat \\
\hline
\end{tabular}

Tabel 3. Pemodelan Multivariat

\begin{tabular}{lllc}
\hline Variabel & Nilai $\mathbf{p}$ & OR & $\mathbf{9 5 \%}$ CI \\
\hline Bukti langsung & 0,003 & 13,976 & $2,484-78,641$ \\
Keandalan & 0,147 & 3,708 & $0,632-21,768$ \\
Ketanggapan & 0,725 & 1,694 & $0,090-32,035$ \\
Jaminan & 0,478 & 2,782 & $0,165-46,892$ \\
Empati & 0,424 & 3,069 & $0,196-48,040$ \\
\hline
\end{tabular}

regresi logistik ganda (seleksi bivariat), yaitu keandalan (reability), ketanggapan (renponsiveness), jaminan (assurance) bidan, empati (emphaty), dan bukti langsung (tangible) dengan nilai $\mathrm{p} \leq 0,25$ (Tabel 2). Hasil analisis regresi logistik ganda menunjukkan bahwa variabel bukti langsung berhubungan signifikan dengan kepuasan pasien program Jampersal dengan nilai $\mathrm{p}<0,05(0,003)$ dengan OR sebesar 13,9 kali (Tabel 3). Dimensi mutu bukti langsung buruk berisiko 13,9 untuk tidak puas terhadap pelayanan program Jampersal di RSUD Kabupaten Rokan Hulu dibandingkan dengan responden yang memiliki dimensi mutu bukti langsung yang baik.

\section{Pembahasan}

Penelitian ini menemukan bahwa responden dengan dimensi mutu bukti langsung buruk berisiko 14 kali untuk tidak puas terhadap pelayanan program Jampersal di RSUD Kabupaten Rokan Hulu dibandingkan dengan responden yang memiliki dimensi mutu bukti langsung yang baik. Hal ini dapat dilihat bahwa dalam dimensi mutu tangible (bukti langsung) di RSUD Rokan Hulu masih banyak fasilitas sarana dan prasarana yang kurang memadai. Masih ditemukan alat-alat yang rusak dan ruangan yang kotor sehingga pasien merasa kurang nyaman jika harus mengikuti program Jampersal yang menempati di ruang kelas III. Berdasarkan penelitian Ainy $\mathrm{dkk},{ }^{8}$ pada dimensi tangible ada tiga atribut dengan persentase kesesuaian di bawah nilai rata-rata total. Pertama, kenyamanan ruang tunggu; kedua, kenyamanan dan kerapian ruang pengobatan; ketiga, kelengkapan, kesiapan dan kebersihan alat-alat yang digunakan. Pada penelitian Hafizurrachman, ${ }^{9}$ bahwa untuk meningkatkan kebersihan terhadap fasilitas dengan mengintensifkan upaya petugas cleaning service untuk bekerja lebih giat atau supervisi yang intensif disamping upaya pihak rumah sakit untuk mengajak pasien atau pengunjungnya menjaga kebersihan lingkungan rumah sakit. Hal ini juga didukung oleh penelitian Ayubi, ${ }^{10}$ bahwa kualitas atribut struktur yang termasuk ke dalam dimensi bukti langsung yaitu kelengkapan sarana mendapat penilaian terendah, dimana pada situasi ini banyak ditemukan kelengkapan fasilitas pelayanan kesehatan paling sering menjadi keluhan bagi masyarakat karena secara objektif dapat diidentifikasi. Pada penelitian Irfan, ${ }^{11}$ rendahnya kualitas layanan kesehatan bagi pasien rumah sakit umum dibandingkan swasta karena banyaknya faktor yang memengaruhi dimensi mutu. Faktor-faktor ini meliputi dana dari pemerintah, kurangnya minat pemerintah dalam pengembangan proyek kesehatan yang baru di daerah perdesaan dan rumah sakit umum terbebani karena tingkat pertumbuhan penduduk dan urbanisasi.

Hasil penelitian ini juga sejalan dengan penelitian Hermanto dkk, ${ }^{12}$ yaitu ada hubungan yang signifikan antara persepsi mutu bukti langsung pelayanan kebidanan dengan kepuasan pasien (nilai $\mathrm{p}=0,0001$; $\mathrm{OR}=11,866$ ). Dinyatakan bahwa responden yang berpersepsi kurang baik pada bukti langsung mempunyai kemungkinan yang jauh lebih besar yaitu 11,87 untuk tidak puas dibandingkan yang berpersepsi baik. Semakin tidak baik persepsi responden terhadap mutu bukti langsung pelayanan kebidanan, maka responden semakin tidak puas terhadap layanan kebidanan. Dapat disimpulkan bahwa untuk meningkatkan kepuasan pasien maka perlu perbaikan mutu pelayanan yang terkait dengan bukti langsung berupa sarana dan prasarana kebidanan yang memadai untuk mendukung tercapainya tujuan pembangunan MDGs.

Menurut Kurniasari dan Kuntjoro, ${ }^{13}$ kualitas sebuah pelayanan kesehatan sangat dikaitkan dengan kehendak dalam memenuhi kebutuhan para pemakai jasa pelayanan kesehatan baik berupa bukti fisik sehingga semakin sempurna pemenuhan kebutuhan tersebut semakin baik pula kualitas pelayanan. Pada penelitian Hizrani, ${ }^{14}$ bahwa pelanggan memang harus dipuaskan, sebab jika pelanggan merasa tidak puas akan pelayanan yang diberikan dia akan mencari tempat lain yang lebih memuaskan. Jika pelanggan sudah terpenuhi kepuasannya, tingkat loyali- 
tasnya akan baik pula. Hal ini dapat terlaksana dengan memberikan pelayanan yang berkualitas dan mampu memenuhi kebutuhan pasien. Sesuai dengan penelitian Andriani, ${ }^{15}$ yang menunjukkan hasil bahwa tinggi rendahnya tingkat kepuasan pasien dipengaruhi oleh tinggi rendahnya kualitas pasien. Indikator kepuasan pasien rawat inap rumah sakit dapat diterapkan dengan meningkatkan manajemen pelayanan rumah sakit sehingga kepuasan pasien dapat terwujud. Selain itu, bagi pasien kualitas pelayanan dapat dijadikan salah satu faktor untuk memilih rumah sakit yang berkualitas.

Tangibles (bukti langsung) adalah kemampuan suatu perusahaan dalam menunjukkan eksistensinya kepada pihak eksternal penampilan kantor dan karyawan, kemampuan sarana dan prasarana fisik perusahaan (termasuk fasilitas komunikasi), serta lingkungan sekitarnya adalah bukti nyata dari pelayanan yang diberikan oleh pembeli jasa. Penampilan pelayanan tidak hanya sebatas pada penampilan fisik bangunan yang megah tetapi juga penampilan petugas dan ketersediaan sarana dan prasarana penunjang. ${ }^{16} \mathrm{Hal}$ ini didukung dengan penelitian Bata $\mathrm{dkk},{ }^{17}$ bahwa ada hubungan yang signifikan antara tangibles (bukti fisik) dengan kepuasan pasien pengguna akses sosial dengan nilai $\mathrm{p}=0,001$. Penelitian Waryono, ${ }^{18}$ menunjukkan bahwa adanya pengaruh positif dan signifikan pada dimensi tangibles (bukti langsung) terhadap kepuasan pasien/pelanggan salah satu bukti langsung yang ada, yaitu kenyamanan di ruang pelayanan dan ruang tunggu. Selain itu, penelitian Purnama, ${ }^{19}$ berhubungan signifikan antara dimensi bukti langsung dengan kepuasan pasien. Penelitian Azizan, ${ }^{20}$ dan Gunawardane, ${ }^{21}$ menunjukkan bahwa dimensi bukti langsung adalah dimensi yang paling berpengaruh dan berhubungan dengan kualitas pelayanan yang dirasakan.

Bukti fisik yang ditunjukkan jika sesuai penerapannya dalam memberikan pelayanan kepada pasien dan berhubungan dengan kepuasan konsumen atas pelayanan yang diterima. Artinya, bukti fisik dalam kualitas pelayanan sangat penting dalam meningkatkan kepuasan pasien atas pelayanan yang diterima. Sesuai dengan teori pada hasil penelitian Loveloc dan Wright, 22 menyimpulkan bahwa tampilan fisik (tangible) memberi petunjuk tentang kualitas jasa dan akan mempengaruhi pelanggan dalam menilai jasa tersebut sehingga perlu dipikirkan sifat dari bukti fisik bagi pelanggan. Hal ini juga didukung oleh penelitian El Haj, ${ }^{23}$ bahwa Institusi pelayanan kesehatan mengambil tantangan untuk meningkatkan kualitas pelayanan dan jasa untuk ditawarkan kepada pelanggan (pasien) dan memuaskan kebutuhan mereka.

\section{Kesimpulan}

Proporsi pasien program Jampersal yang memiliki kepuasan terhadap mutu pelayanan kebidanan sebanyak
67 orang $(72,8 \%)$ dari 92 sampel. Variabel independen yang mempunyai hubungan yang signifikan dengan kepuasan pasien program Jampersal adalah variabel bukti langsung dengan nilai $\mathrm{p}<0,05(0,003)$.

\section{Daftar Pustaka}

1. Sedyaningsih ER. Mewujudkan kemandirian kesehatan masyarakat berbasis preventif dan promotif. Seminar dalam rangkaian acara Dies Natalis FKM UNDIP ke-25. Semarang; 2010.

2. Siregar M. Upaya dan tantangan dalam peningkatan program kesehatan ibu, bayi baru lahir dan anak (KIBBLA) di Sumatra Utara dalam seminar "Menyongsong Millenium Development Goals 2015 melalui Pembangunan Kesehatan Masyarakat”. Medan: Fakultas Kesehatan Masyarakat Universitas Sumatera Utara; 2007.

3. Departemen Kesehatan Republik Indonesia. Pedoman pemantauan wilayah setempat kesehatan ibu dan anak (PWS-KIA). Jakarta: Departemen Kesehatan Republik Indonesia; 2009.

4. Satrianegara MF, Saleha S. Buku ajar organisasi dan manajemen pelayanan Kesehatan serta Kebidanan. Jakarta: Salemba Medika; 2009.

5. Nugroho. Perilaku konsumen. Jakarta: Kencana; 2003.

6. Thoha M. Perilaku organisasi. Jakarta: Raja Grafindo Persada; 2002.

7. RSUD Rokan Hulu. Data rekam medis RSUD Rokan Hulu. Pasir Pangaraian: RSUD Rokan Hulu; 2012.

8. Ainy A, Misnaniarti, Fajar NA. Importance performance analysis pelayanan jaminan sosial kesehatan di Puskesmas Swakelola Pembina. Kesmas Jurnal Kesehatan Masyarakat Nasional. 2012; 7 (3): 105-10.

9. Hafizurrachman. Kepuasan pasien dan kunjungan rumah sakit. Kesmas Jurnal Kesehatan Masyarakat Nasional. 2009; 4 (1): 10-7.

10. Ayubi D. Penilaian kualitas pelayanan puskesmas dengan model donabedian: studi kasus puskesmas di Kota Depok. Kesmas Jurnal Kesehatan Masyarakat Nasional. 2009; 4 (1): 24-8.

11. Irfan SM, Ijas A. Comparison of service quality between private and public hospitals: empirical evidences from Pakistan. Journal of Quality and Technology Management. 2011; 7 (1): 1-22.

12. Hermanto D, Mawarni A, Ratna L. Persepsi mutu pelayanan dalam kaitannya dengan kepuasan pasien rawat inap kebidanan RSUD dr. H. Soemarno Sosroatmodjo Bulungan Kalimantan Timur. Jurnal Penelitian Kesehatan Suara Forikes. 2012; 3 (2): 60-8.

13. Kurniasari A, Kuntjoro T. Analisis kebutuhan pelanggan Puskesmas Pijoan Baru Provinsi Jambi [tesis]. Yogyakarta: Fakultas Kedokteran Universitas Gajah Mada: 2006.

14. Hizrani M. Analisis kepuasan pasien rawat inap terhadap mutu pelayanan dan hubungannya dengan minat beli ulang di RS X Jakarta. Jurnal Manajemen dan Admistrasi Rumah Sakit Indonesia (MARSI). 2012; 6 (1).

15. Andriani S, Sunarto. Hubungan kualitas pelayanan kesehatan dengan kepuasan pasien rawat inap di Badan Pelayanan Kesehatan Rumah Sakit Umum Daerah Kabupaten Magelang. Jurnal Kesehatan. 2009; 2 (1): 71 9.

16. Lupiyoadi R. Manajemen pemasaran jasa. Jakarta: Salemba Empat; 2006.

17. Bata YW, Arifin MA, Darmawansyah. Hubungan kualitas pelayanan kesehatan dengan kepuasan pasien pengguna akses sosial pada pelayanan rawat inap di RSUD Lakipadada Kabupaten Tana Toraja Tahun 2013 
[online]. Makasar: Universitas Hasanuddin; 2013 [diakses tanggal 15 Juni 2013]. Diunduh dalam: repository.unhas.ac.id/bitstream/handle/123456789/jurnal.pdf.

18. Waryono, Purwanti NS, Palestin B. Pengaruh kepuasan masyarakat terhadap pemanfaatan pelayanan kesehatan di Puskesmas Kota Yogyakarta dan RSUD Kota Yogyakarta tahun 2009. Jurnal Penelitian BAPPEDA. 2011; 6 (6).
19. Purnama S. Analisis pengaruh kualitas pelayanan kesehatan terhadap kepuasan pemohon bagian perijinan pelayanan kesehatan tradisional di Suku Dinas Pelayanan Kesehatan Kodya Jakarta Barat. Forum Ilmiah. 2013; 10 (2): 307-23.

20. Lovelock C, Wright LK. Manajemen pemasaran jasa. Edisi Bahasa Indonesia. Jakarta : Penerbit Indeks; 2005. 